\title{
Exploration of Mechanisms of Joint Deterioration in Concrete Pavements regarding Interfacial Transition Zone
}

\author{
Xin Wang, ${ }^{1}$ Jiake Zhang $\mathbb{D}^{2}{ }^{2}$ Xuhao Wang $\left(\mathbb{D},{ }^{3,4}\right.$ Peter Taylor, ${ }^{5}$ Kejin Wang, ${ }^{6}$ \\ and Xinjian Sun ${ }^{7,8}$ \\ ${ }^{1}$ Ph.D. Student, Civil, Construction and Environmental Engineering, Town Engineering Building, Iowa State University, \\ Ames, Iowa 50014, USA \\ ${ }^{2}$ Research Associate, College of Transportation Engineering, Tongji University, Shanghai, China \\ ${ }^{3}$ Associate Research Scientist, Qinghai University-Tsinghua University Sanjiangyuan University Sanjiangyuan Research Institute, \\ Qinghai University, Xinning, China \\ ${ }^{4}$ Associate Professor, School of Highway Chang'an University, Xi'an, China \\ ${ }^{5}$ Director, National Concrete Pavement Technology Center, Ames, Iowa 50014, USA \\ ${ }^{6}$ Professor, Civil, Construction and Environmental Engineering, Town Engineering Building, Iowa State University, \\ Ames, Iowa 50014, USA \\ ${ }^{7}$ Associate Professor, School of Hydraulic and Electirc Engineering, Qinghai University, Xinning, China \\ ${ }^{8}$ State Key Laboratory of Plateau Ecology and Agriculture, Xinning, China
}

Correspondence should be addressed to Xuhao Wang; wangxh@chd.edu.cn

Received 26 February 2018; Accepted 16 September 2018; Published 27 November 2018

Guest Editor: Jinchang Wang

Copyright (C) 2018 Xin Wang et al. This is an open access article distributed under the Creative Commons Attribution License, which permits unrestricted use, distribution, and reproduction in any medium, provided the original work is properly cited.

As a common issue for cold weather regions, premature deterioration of concrete at joints has been reported in many states. In this paper, the mechanisms of joint deterioration were investigated, and then, experimental investigations were conducted to further verify some of the mechanisms. It was found that freeze-thaw (F-T) damage and salt crystallization are not enough to cause the observed deterioration, but the deterioration near the interfacial transition zone (ITZ) may be the cause of some of the observed phenomena. In the experimental work, samples were tested at $40^{\circ} \mathrm{F}$ in salt solutions to observe the deterioration in the ITZ using the scanning electron microscope (SEM). Concrete tested in $\mathrm{MgCl}_{2}$ solution indicated distress in ITZ under SEM. It was found that ITZ may act as a shortcut for ion transfer to surrounding concrete near the joints and may also be the weak point for cracking due to expansion of the paste.

\section{Introduction}

Sawn joints in concrete pavements are used to control both transverse and longitudinal cracking, which are induced by shrinkage or contraction of the pavement. According to the American Concrete Pavement Association [1], an efficient joint system should accommodate slab movements, transfer load between pavement segments, and divide the concrete slab into practical construction increments. Contraction joints are normally made by saw cutting, with a minimum depth of $1 / 4$ the thickness of slab but not less than $25.4 \mathrm{~mm}$ and a minimum width of $3.18 \mathrm{~mm}$. Saw cutting is conducted when the concrete is mature enough to be cut without spalling, but not too late to allow random cracks in the slab. A sealant is often placed to prevent water from getting into the joint. However, sealants may deteriorate and so allow water to penetrate the saw cut over time, thus increasing the risk of damage within the kerf.

Performance and service life of concrete pavements are heavily dependent on the performance of the joints. Hence, premature joint deterioration is a great concern, particularly in cold weather regions. Figure 1 shows multiple forms of pavement joint deterioration observed in different states [2]. To control or eliminate such pavement deterioration, it is necessary to understand the mechanisms of joint damage. 


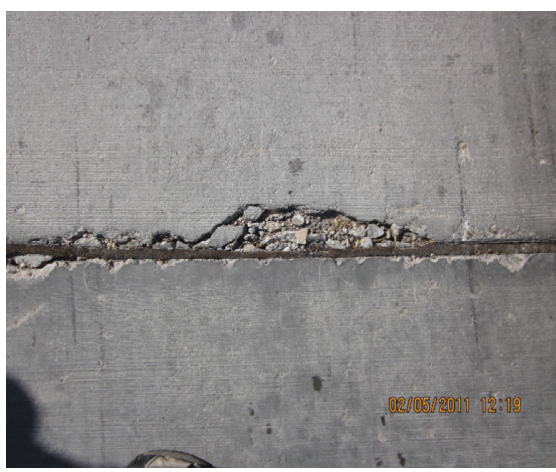

(a)

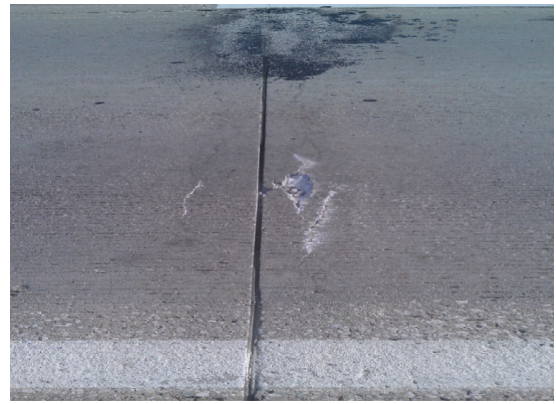

(d)

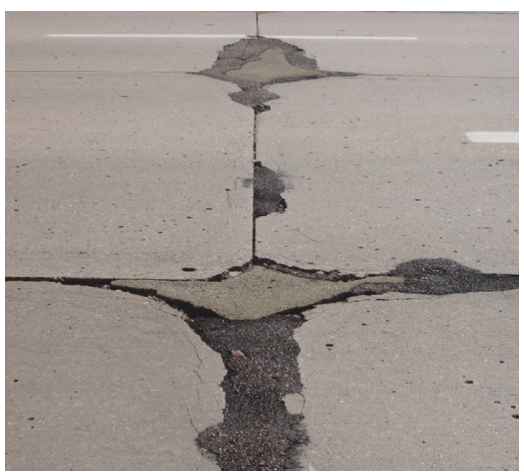

(b)

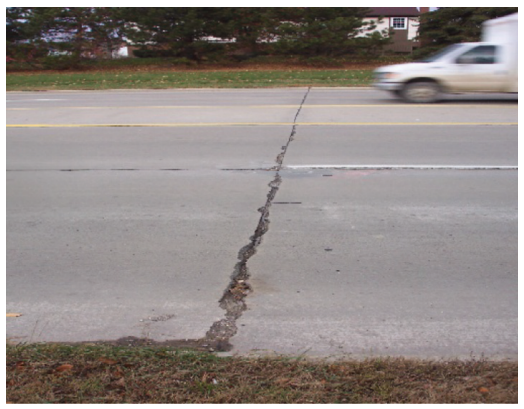

(e)

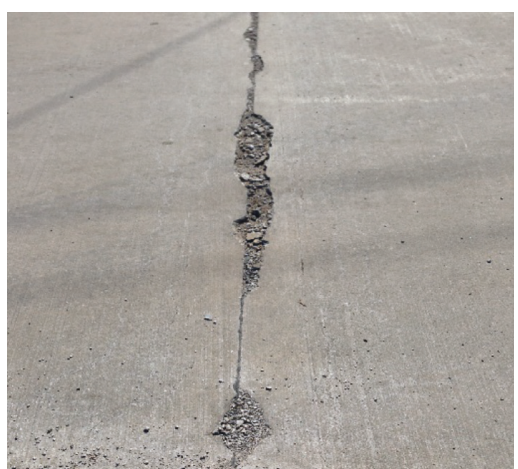

(c)

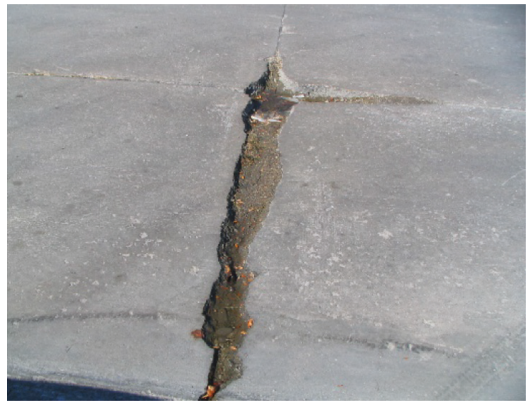

(f)

Figure 1: Photos of joint deterioration from multiple states. (a) Arizona, 2011. (b) Colorado, 2010. (c) Illinois, 2014. (d) Kansas, 2012. (e) Missouri, 2005. (f) Nebraska, 2010.

The objective of this research was to review the current state of knowledge of possible causes of joint deterioration and further investigate the mechanism behind this form of deterioration.

\section{Mechanisms of Joint Deterioration}

Damage is typically observed in two different forms. The first is the formation of small flakes in the paste near the joint (Figure 2(a)). The other form is where cracks form about $25.4 \mathrm{~mm}$ from the exposed face, and exposed aggregate particles are observed (Figure 2(b)). In the latter case, the concrete between the crack and the face is often in good condition. Typically, the crack will form around the coarse aggregate leaving it unusually free of mortar. The cause of this distress has been less well understood.

The current knowledge of joint deterioration indicates that there are four major mechanisms by which concrete joints may deteriorate:

(1) Freezing-thawing (F-T) damage

(2) Salt crystallization

(3) Oxychloride expansion

(4) Interfacial transition zone damage

2.1. Freezing-Thawing Damage. It is widely accepted that the freeze-thaw mechanism is typically associated with concrete that contains marginal air-void systems that are exposed to abundant moisture. Moisture in a joint may be higher than that at the surface because water is trapped due to insufficient drainage of the base layer or the cracks not opening up. Li et al. [3] have observed that for samples with a degree of saturation higher than a critical value of $86-88 \%$, concrete may exhibit damage in a few freeze-thaw cycles. They also found that saturated concrete is unable to resist cyclic F-T, regardless of the air content of concrete, although a properly entrained-air system is effective at delaying critical saturation.

2.2. Salt Crystallization. Deicing salts are applied to roadways in areas that experience snow and ice in order to ensure the safety of traffic on roadways. Salts in pore solutions may crystallize out and form crystals due to changes in external humidity or temperature. A state of supersaturation is required for crystallization to occur. Under supersaturation, the cumulative crystals generate stress on the confining pore walls and cause damage in the solid matrix of a concrete mixture [4]. Using an equation proposed by Correns in 1949 [5] which describes the growth and dissolution of crystals under pressure (Equation (1)), Thaulow and Sahu [4] concluded that potential pressure created by crystallization (159 atm) could be 5 to 10 times the tensile strength of concrete in their example:

$$
P=\frac{R T}{V_{\mathrm{s}}} * \operatorname{Ln} \frac{C}{C_{\mathrm{s}}},
$$

where $P$ is the pressure exerted by growing crystals, $R$ is the gas constant, $0.082 \mathrm{~L}-\mathrm{atm} / \mathrm{mol}, T$ is the absolute 


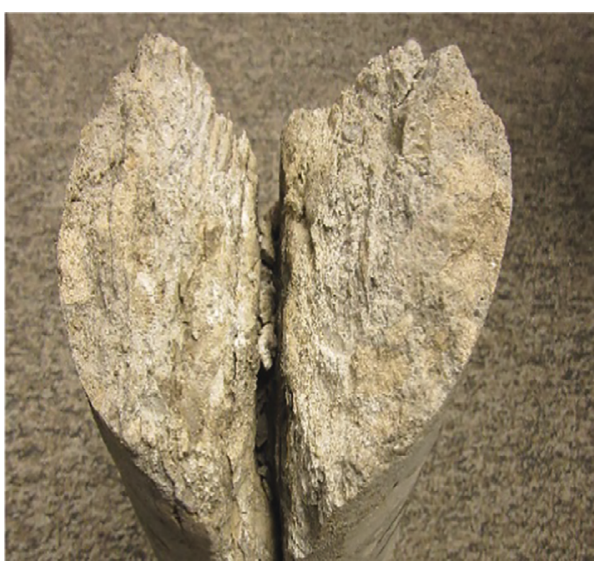

(a)

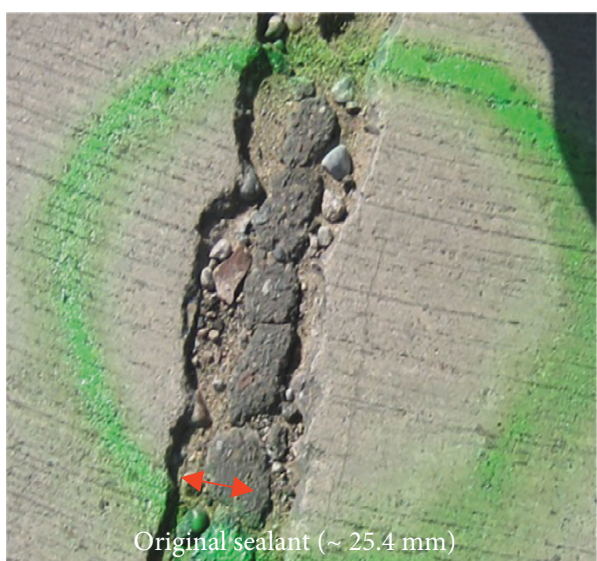

(b)

Figure 2: Typical F-T deterioration: (a) F-T damage and (b) joint deterioration.

temperature, $\mathrm{K}, V_{\mathrm{s}}$ is the molar volume of solid salt in $\mathrm{L} /$ mole, and $C / C_{\mathrm{s}}$ is the degree of supersaturation, where $C$ is the existing solute concentration and $C_{s}$ is the saturation concentration.

2.3. Oxychloride Formation. Certain deicers contain chemicals that may deteriorate concrete pavement. Chloride deicers will increase the concentration of calcium and magnesium in pore water of concrete. At the same time, the chloride is able to react with cement paste and forming a new expansive phase that may be expansive, calcium chloride [6]. The expansive nature of calcium oxychloride can block the concrete pore connection, decrease the fluid transfer property in concrete, and influence the entire concrete matrix [6-8].

Formation of calcium oxychloride occurs at temperature just above freezing $[6,8]$. Both calcium chloride and magnesium chloride can form calcium oxychloride by reacting with calcium hydroxide from the cement paste. Though various forms of calcium oxychloride can be produced based on environmental conditions such as temperature and relative humidity, a common reaction is illustrated in Equation (2). The reaction between magnesium chloride and calcium hydroxide is complex, producing not just calcium oxychloride but also magnesium chloride in secondary reactions [9]:

$$
\begin{aligned}
& 3 \mathrm{Ca}(\mathrm{OH})_{2}+\mathrm{CaCl}_{2}+12 \mathrm{H}_{2} \mathrm{O} \longrightarrow 3 \mathrm{Ca}(\mathrm{OH})_{2} \cdot \mathrm{CaCl}_{2} \\
& \cdot 12 \mathrm{H}_{2} \mathrm{O}
\end{aligned}
$$

When $\mathrm{MgCl}_{2}$ is used as a deicer on concrete pavements, a reaction between $\mathrm{Ca}(\mathrm{OH})_{2}$ from cement hydration and magnesium chloride will produce brucite $\left(\mathrm{Mg}(\mathrm{OH})_{2}\right.$ (Equation (3)). At the same time, the calcium in calcium silicate hydrate (C-S-H) will be replaced by magnesium to produce noncementitious magnesium silicate hydrate (M-SH) (Equation (4)) [8]:

$$
\begin{gathered}
\mathrm{Ca}(\mathrm{OH})_{2}+\mathrm{MgCl}_{2} \longrightarrow \mathrm{Mg}(\mathrm{OH})_{2}+\mathrm{CaCl}_{2} \\
\mathrm{C}-\mathrm{S}-\mathrm{H}+\mathrm{MgCl}_{2} \longrightarrow \mathrm{M}-\mathrm{S}-\mathrm{H}+\mathrm{CaCl}_{2}
\end{gathered}
$$

As the secondary reaction, brucite produced from Equation (3) will react with remaining $\mathrm{MgCl}_{2}$ to produce magnesium oxychloride (Equation (5)). Two phases of magnesium oxychloride are reported to exist, with either 3 or $5 \mathrm{Mg}(\mathrm{OH})_{2}$ molecules ((3 or 5$\left.) \mathrm{Mg}(\mathrm{OH})_{2} \mathrm{MgCl}_{2} \cdot 8 \mathrm{H}_{2} \mathrm{O}\right)$ [8].

$\mathrm{CaCl}_{2}$ produced from Equation (3) may also contribute to formation of calcium oxychloride [10], and the process of calcium oxychloride formation is in a similar stepwise reaction as $\mathrm{MgCl}_{2}$ solutions (Equation (2)). Both calcium oxychloride and magnesium oxychloride have been reported to be expansive and destructive in the concrete system $[8,11]$ :

$$
\begin{aligned}
(3 \text { or } 5) \mathrm{Mg}(\mathrm{OH})_{2}+\mathrm{MgCl}_{2}+8 \mathrm{H}_{2} \mathrm{O} \longrightarrow & (3 \text { or } 5) \mathrm{Mg}(\mathrm{OH})_{2} \\
& \cdot \mathrm{MgCl}_{2} \cdot 8 \mathrm{H}_{2} \mathrm{O}
\end{aligned}
$$

Formation of magnesium oxychloride is dependent on the concentration of magnesium chloride $[12,13]$. M-S-H and $\mathrm{Mg}(\mathrm{OH})_{2}$ are thermodynamically more stable than C-S-H and $\mathrm{Ca}(\mathrm{OH})_{2}$, so it is preferable for $\mathrm{C}-\mathrm{S}-\mathrm{H}$ and $\mathrm{Ca}(\mathrm{OH})_{2}$ to change into $\mathrm{M}-\mathrm{S}-\mathrm{H}$ and $\mathrm{Mg}(\mathrm{OH})_{2}$, both of which are expansive. Monosi and Collepardi also reported that the oxychloride formation proceeds faster at temperatures between 4 and $10^{\circ} \mathrm{C}$, while Peterson et al. [13] proposed that a phase change of calcium oxychloride may occur between $0^{\circ} \mathrm{C}$ and $50^{\circ} \mathrm{C}$.

2.4. Interfacial Transition Zone Damage. The interfacial transition zone (ITZ) in concrete is a $10-50 \mu \mathrm{m}$ zone between cement paste and coarse aggregates formed during hydration of cement particles against aggregate surfaces [14, 15]. ITZ has a higher porosity than bulk-hydrated cement paste. Due to the high porosity and their high connectivity, property of transportation of fluids is increased in the ITZ, 


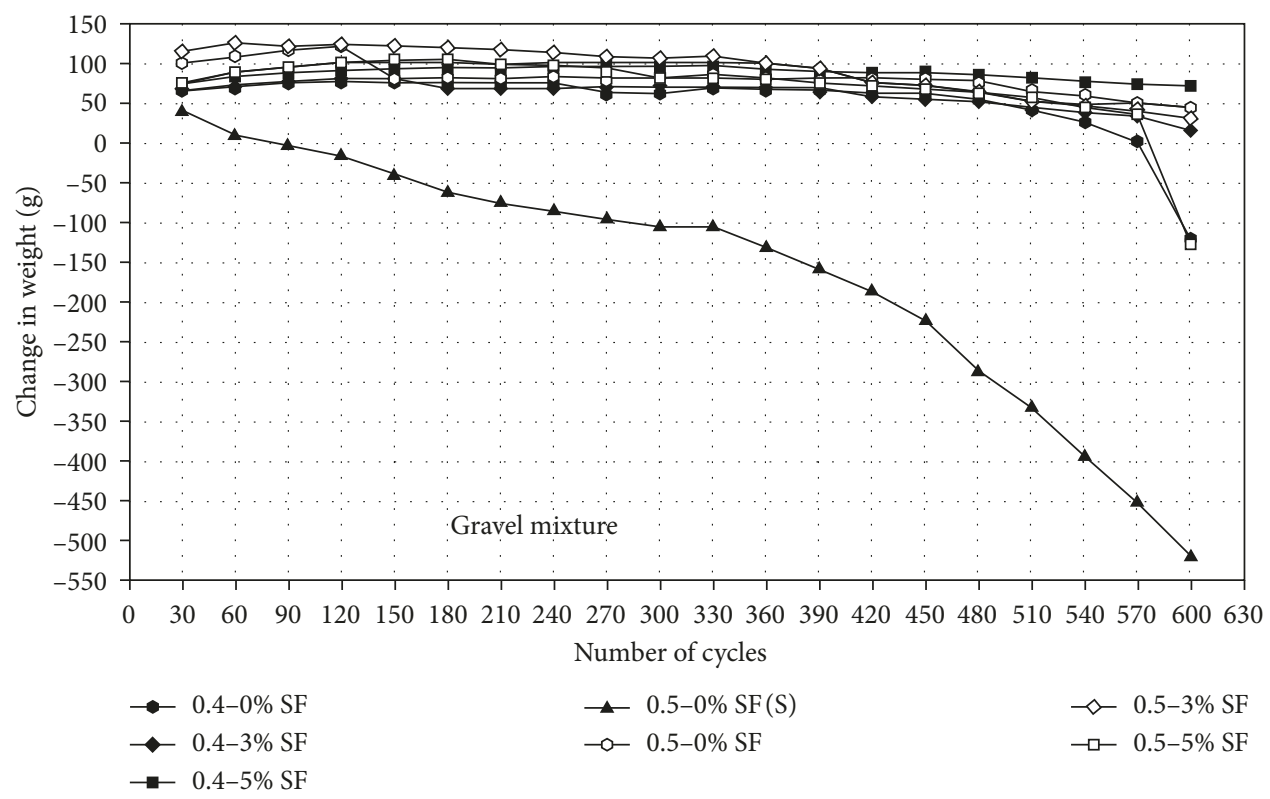

FIGURE 3: Weight change of beams for 600 freezing and thawing cycles (W/C ratio $0.4 / 0.5$; silica fume content $0 \%, 3 \%$, and $5 \%$; $0.5-0 \%$ SF (S) sample with $\mathrm{W} / \mathrm{C}=0.5,0 \%$ silica fume, soaked in $\mathrm{NaCl}$ ).

facilitating movement of chloride ions [16] thus increasing the amount of paste that may react with the chlorides as discussed above.

In a previously reported project, Taylor et al. [17] observed mass loss in samples cycled in 3\% sodium chloride solution using ASTM C666 (Figure 3). In comparing with samples with no silica fume, samples with an improved ITZ by silica fume were more durable. It was also reported that chloride and calcium ions appeared concentrated in the ITZ near the surface in these samples, indicating that the interfacial transition zone could be preferentially penetrated and attacked by deicers (Figure 4). They concluded that the ITZ is playing a significant part in the formation of incremental cracks about $25.4 \mathrm{~mm}$ from, and parallel to, the joint surface.

It is well known that the solubility of calcium solutions increases with decreasing temperature. It was hypothesized that, as temperatures are reduced in a freezing system, then an ITZ containing high amounts of $\mathrm{Ca}(\mathrm{OH})_{2}$ might tend to dissolve more readily than the bulk C-S-H system nearby. Such dissolution would encourage separation of the coarse aggregate particles from the paste. In addition, chloride ions can penetrate into hydrated cement pastes [18], and leach out $\mathrm{Ca}(\mathrm{OH})_{2}$, consequently increasing porosity and susceptibility to freeze-thaw deterioration [19].

2.5. Summary of Mechanisms. The F-T damage and salt crystallization stresses discussed above can be quantified. Based on an equation proposed by Correns [5], Zhang [21] calculated the crystallization pressure to be about $2600 \mathrm{kPa}$ in the ITZ. The osmotic pressure is about $1100 \mathrm{kPa}$ according to Valenza and Scherer [20]. The total pressure due to these mechanisms is thus about $3700 \mathrm{kPa}$.

Figure 5 shows a deteriorated sample exposed to $3 \% \mathrm{NaCl}$ solution, and part of aggregate on the corner is smooth and clean with no mortar after 10 cycles of F-T. This is a concrete sample with 0.45 water-to-cementitious material ratio and $10 \%$ silica fume. The flexural strength of the sample was likely above $4500 \mathrm{kPa}$ [22] which is greater than the imposed stress. The cumulative pressure caused by osmotic pressure and salt crystallization is therefore not enough to cause the deterioration in Figure 5. This suggests that some other mechanism is in play, such as calcium oxychloride expansion, resulting in the paste being separated from the aggregate in the ITZ.

\section{Materials and Methods}

Therefore, the purpose of the work discussed below was to study whether the formation and expansion of oxychloride was a part of mechanism causing the deterioration observed in Figures 2 and 5.

3.1. Materials, Mix Proportion, Curing Condition, and Specimen Preparation. Materials used in this study include the following:

(i) Coarse aggregate: one inch nominal maximum size of round gravel (specific gravity $(\mathrm{SpG})=2.66$, absorption $=0.3 \%$, and dry-rodded unit weight $=$ $1541 \mathrm{~kg} / \mathrm{m}^{3}$ )

(ii) Fine aggregate: No. 4 sieve size nominal maximum size river sand $(\mathrm{SpG}=2.68$, absorption $=0.6 \%$, and fineness modulus $=3.08$ )

(iii) Portland cement: ASTM C150 Type I

(iv) Supplementary cementitious materials (SCMs): ASTM C618 Class C fly ash and silica fume

Mixtures used in this study had a constant water-tocementitious material ratio $(\mathrm{w} / \mathrm{cm})$ of 0.45 and 


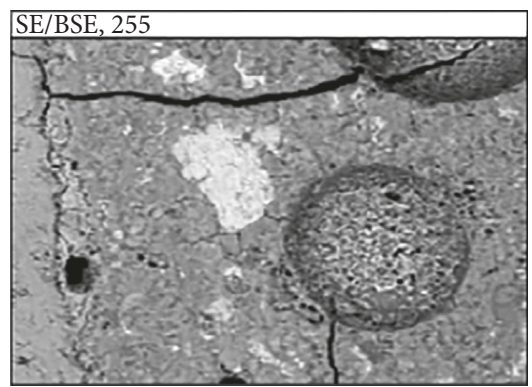

(a)

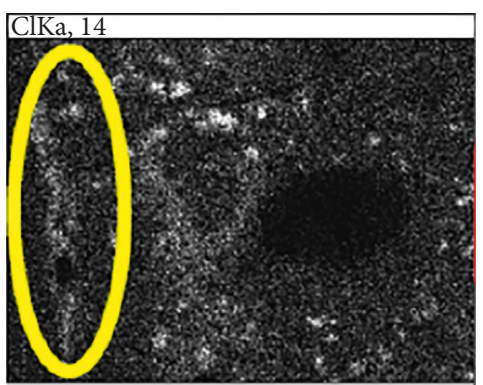

(b)

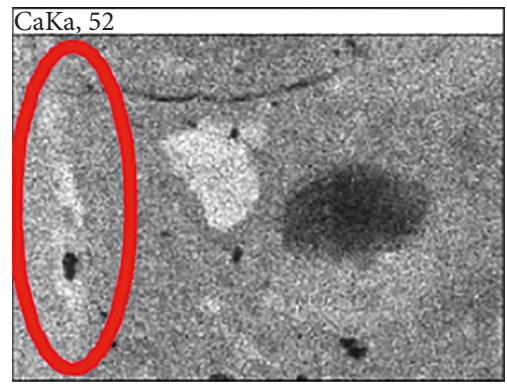

(c)

Figure 4: SEM map analysis on distressed samples under cyclic freeze thaw in $\mathrm{CaCl}_{2}$ (calcium and sodium).

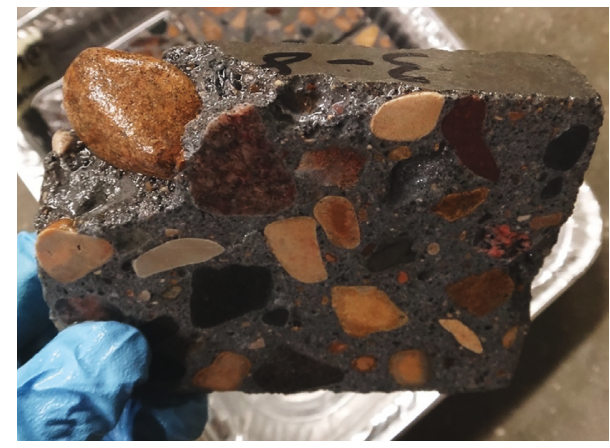

Figure 5: Sample exposed to $3 \% \mathrm{NaCl}$ solution showing washed aggregate on the corner.

TABLE 1: Mixture proportions.

\begin{tabular}{lc}
\hline Material & Quantity \\
\hline Cementitious materials $\left(\mathrm{kg} / \mathrm{m}^{3}\right)$ & 335 \\
Type I cement & $80 \%$ \\
C fly ash & $20 \%$ \\
Water $\left(\mathrm{kg} / \mathrm{m}^{3}\right)$ & 151 \\
Water-to-cementitious material ratio & 0.45 \\
Course aggregate $\left(\mathrm{kg} / \mathrm{m}^{3}\right)$ & 1125 \\
Fine aggregate $\left(\mathrm{kg} / \mathrm{m}^{3}\right)$ & 666 \\
\hline
\end{tabular}

a cementitious material content of $335 \mathrm{~kg} / \mathrm{m} 3$. Mixture parameters are shown in Table 1.

Concrete mixing and curing were conducted in accordance with ASTM C 192. Air content, slump, and unit weight were measured after mixing. Two $7.6 \times 10.2 \times 40.6 \mathrm{~cm}$ beams were cast from each mix. Sample preparation comprised 3 days wet curing followed by exposure to air until 28 days of age. Beams were cut into $7.6 \times 10.2 \times 6.35 \mathrm{~cm}$ prisms using

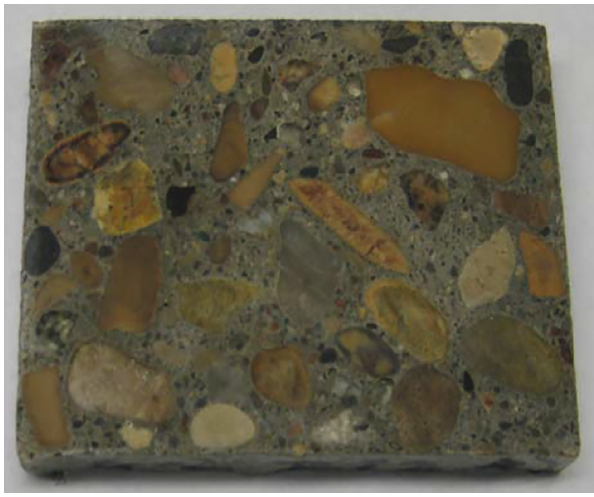

Figure 6: Saw cut slice sample from concrete beam.

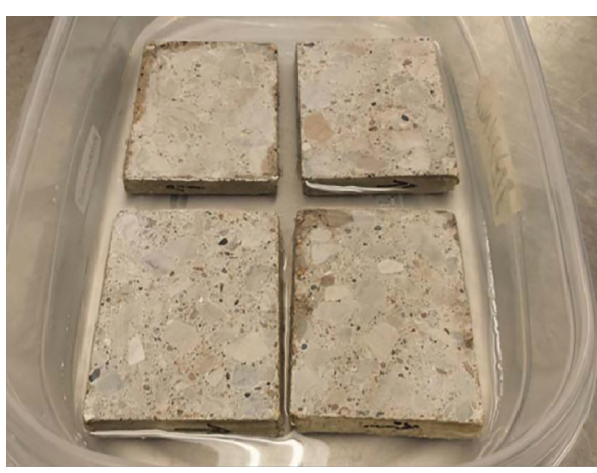

FIGURE 7: Samples partially immersed in deicers.

a diamond saw at 28 days (Figure 6). The section thickness was selected to increase the likelihood that a single aggregate, and its associated ITZ, would percolate from face to face thus accelerating distress effects associated with the ITZ. 

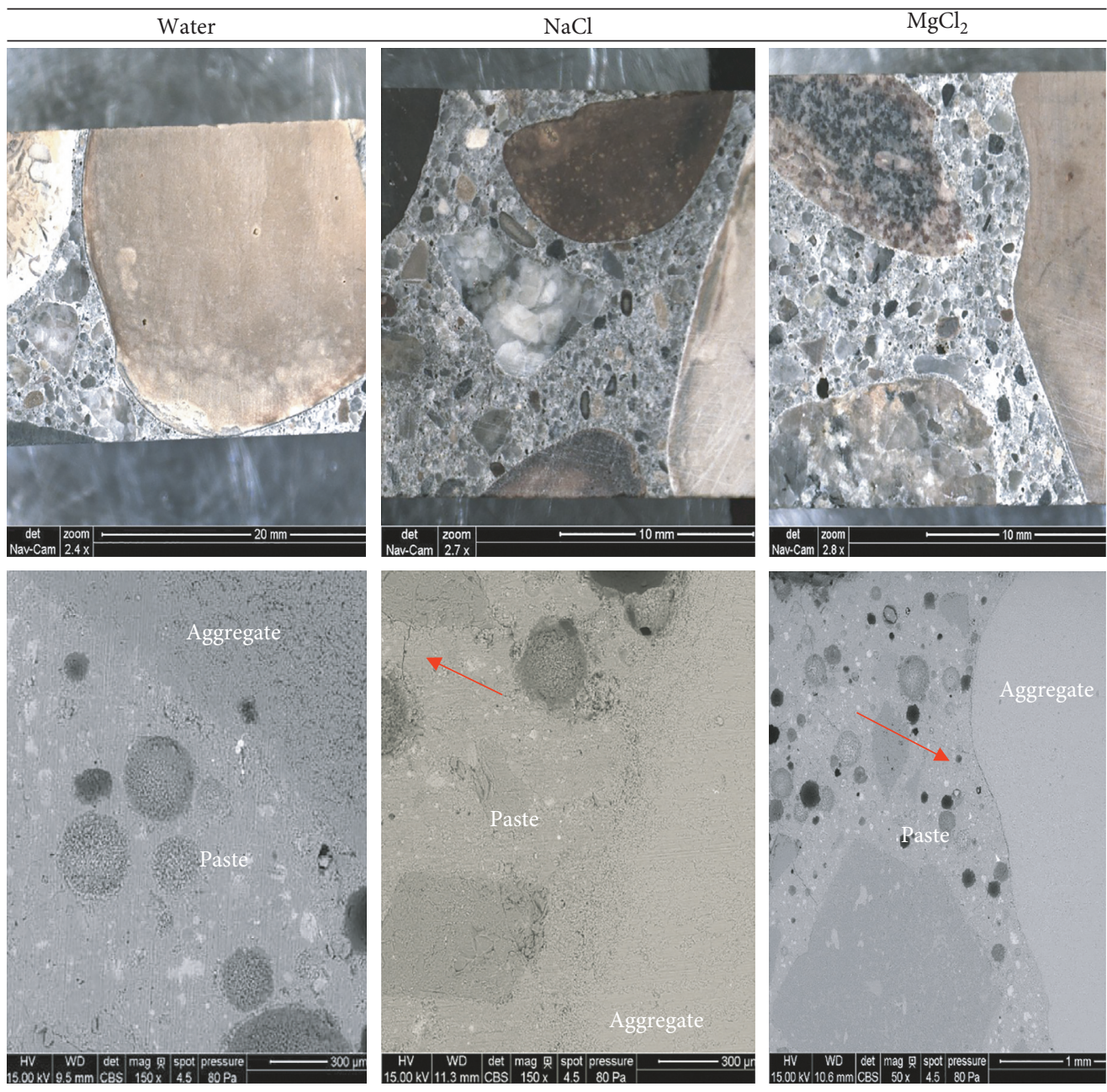

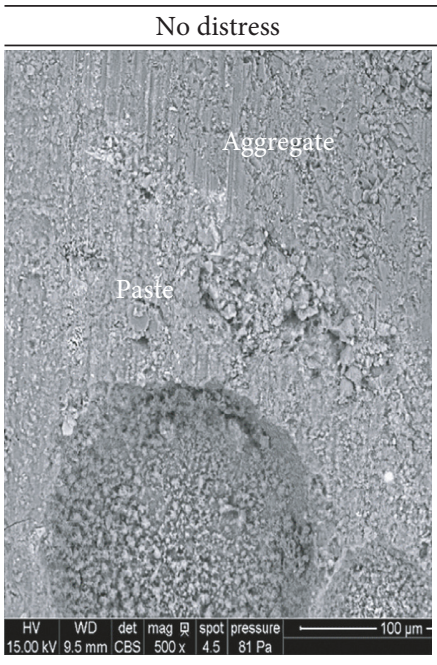

No distress

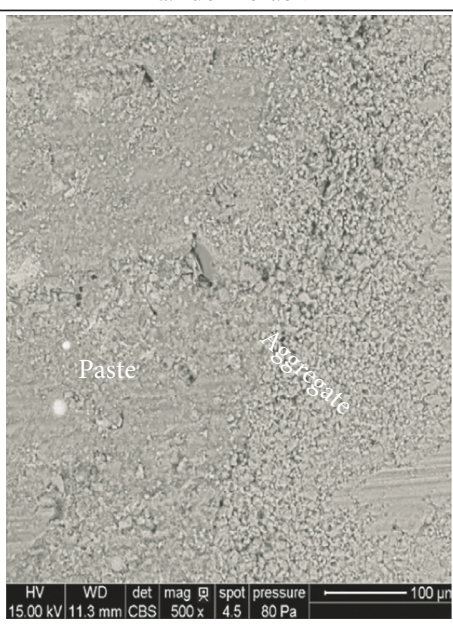

No distress

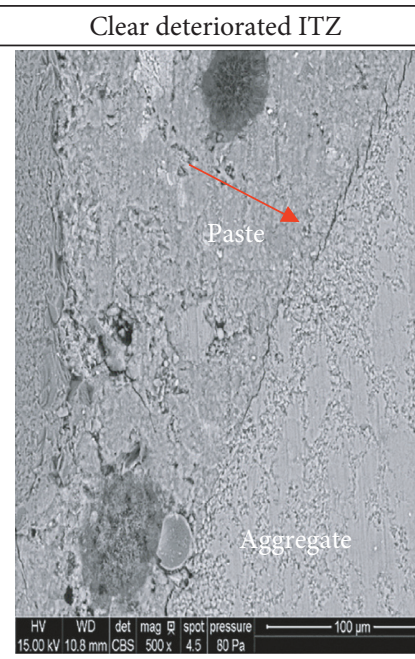

Clear deteriorated ITZ (line between aggregate and paste)

FIGURE 8: SEM images of sample soaked in water, $\mathrm{NaCl}$, and $\mathrm{MgCl}_{2}$ for 56 days.

All samples were vacuum saturated in accordance with ASTM C1202 for 24 hours using the following solutions: 3\% sodium chloride $(\mathrm{NaCl}), 3 \%$ magnesium chloride $\left(\mathrm{MgCl}_{2}\right)$, and water.
3.2. Test Procedures. Six slices were placed in a pan, partially submerged in assigned solutions (Figure 7), and stored at $4^{\circ} \mathrm{C}$ for 56 days. The low, constant temperature was selected to remove the effects of freezing, while enhancing potential 


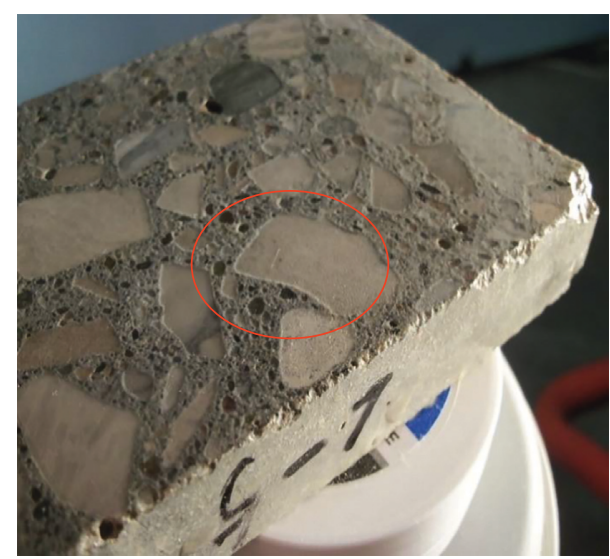

Figure 9: Photo of sample after 56 days in $\mathrm{MgCl}_{2}$ : paste was pushed above aggregate.

dissolution of calcium compounds and formation of oxychloride compounds. The temperature was also selected based on distress reported by Sutter et al. [6]. Photos were taken regularly to track the condition of the sample surface. After 56 days of testing, specimens were split and polished before being examined in a scanning electron microscope. Samples were examined under FEI Quanta 250 FE-SEM at a voltage of $15 \mathrm{kV}$. SEM images from samples are presented in Figure 8.

\section{Results and Discussion}

It is observed that the samples soaked in water did not exhibit any distress, as was expected, since no F-T cycles were applied. Likewise, neither osmotic pressure nor critical saturation should occur.

For samples soaked in $\mathrm{NaCl}$, there was some microcracking in the paste matrix, and the zone between paste and aggregate was undamaged. A possible explanation for this damage is the reactions between aluminate phases of the matrix and deicer solutions [8].

SEM images of samples soaked in $\mathrm{MgCl}_{2}$ showed cracking in the boundary between aggregate and paste (Figure 8). In addition, Figure 9 shows that the paste was pushed above the aggregate, indicating expansion in the paste. It is likely that the damage is due to the paste expanding away from the aggregate particles. This type of deterioration was more prevalent closer to the face of the sample exposed to solution, which is consistent with distress being associated with solutions penetrating the system from an exposed face.

Zhang et al. [23] used the same mix proportions and materials to observe the influence of the ITZ on F-T resistance of concrete mixtures. Samples with 0, 5, and 10\% silica fume were tested in a variety of salt solutions $(\mathrm{NaCl}$, $\mathrm{MgCl}_{2}, \mathrm{CaCl}_{2}$, and water) in F-T cycles. They found that samples tested in water for 35 cycles remained in good condition. This indicated that the paste system was able to resist F-T cycling without becoming critically saturated as discussed in F-T damage.

For samples soaked in $3 \% \mathrm{MgCl}_{2}$, whole aggregate particles were observed to be removed in several samples

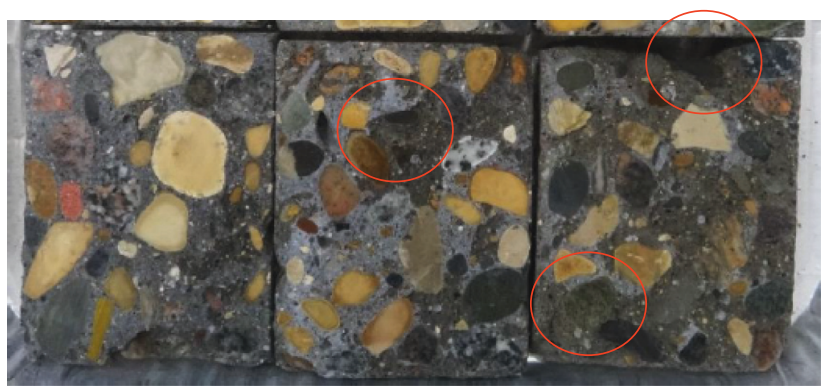

Figure 10: Samples exposed to $\mathrm{MgCl}_{2}$ solution during F-T. Left to right: $10 \%, 5 \%$, and $0 \%$ silica fumes [23]; sample on right with no silica fume lost some aggregates during F-T.

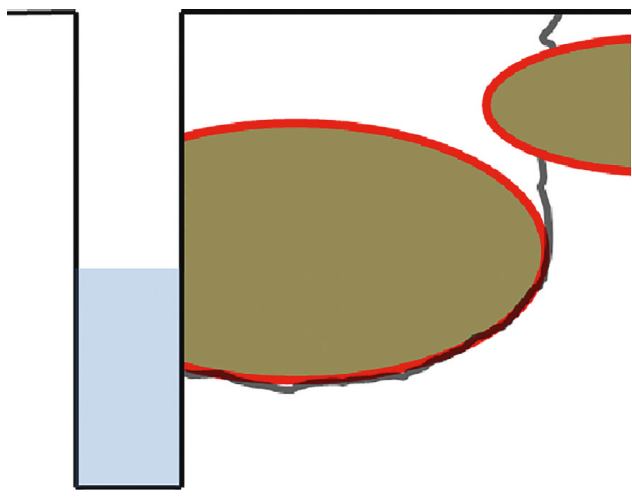

(a)

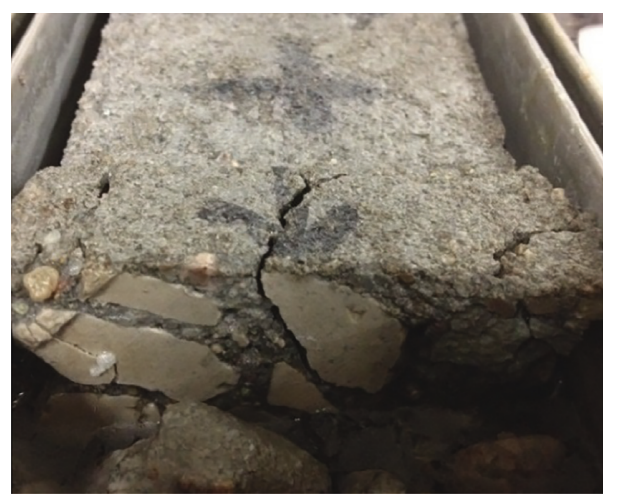

(b)

Figure 11: Crack developing out of a saturated ITZ. (a) Schematic sketch of the theory. (b) Laboratory observation supporting the theory.

(Figure 10). This is again an indicative of aggregate particles being separated from the paste, likely due to expansion of the paste tied with damage in the ITZ.

To explain the phenomenon in Figure 2(b), the following mechanisms may be occurring:

(i) Salt solution is trapped in the kerf of a sawn joint, either because it has not cracked out or the base material below the crack is impermeable.

(ii) Salt solution is preferentially transported around coarse aggregate particles through the ITZ. 
(iii) Oxychloride compounds are formed in the paste around and near the aggregate particles.

(iv) The paste expands, setting up tensile stresses and so cracking in the ITZ. Any dissolution of the ITZ will accelerate this damage.

(v) Cracks are propagated under traffic through the paste to the top surface, typically parallel to and about 1.9 to $2.5 \mathrm{~cm}$ from the sawn face. Aggregates are either removed and left, paste free, loose in the joint, or remained in the concrete, projecting into the joint.

\section{Conclusion}

Joint deterioration in sawn pavements has been found in many cold regions of the United States. The major mechanisms by which concrete joints may deteriorate include (1) freezing-thawing (F-T) damage, (2) salt crystallization, and (3) oxychloride expansion. The interfacial transition zone (ITZ) between cement paste and aggregate permits more salt solution to penetrate around aggregate particles and potentially accelerates the joint deterioration.

By reviewing the previous work and testing samples subjected to soaking and F-T cycles, a mechanism has been described that explains the observed formation of so-called incremental cracks at joints. Solutions containing magnesium and calcium chloride appear to be penetrating the exposed ITZ around coarse aggregate particles in nondraining joints (Figure 11). The solution is reacting with hydrated cement paste to form oxychloride compounds near the aggregate particles. The paste expands, separating from the aggregates and causing cracks to propagate to the surface under traffic.

\section{Data Availability}

The data generated from this research are available upon request to the corresponding author.

\section{Conflicts of Interest}

The authors declare that they have no conflicts of interest.

\section{Acknowledgments}

The present study is an extension of Dr. Jiake Zhang's PhD work "Investigation of deterioration of joints in concrete pavements" (2013). This work was funded by the National Concrete Pavement Center, Ames, Iowa. This study was also partially supported by the National Natural Science Foundation Project (NSFC 51868066) and the Qinghai Science \& Technology Department Natural Science Foundation Project (2018-ZJ-931Q).

\section{References}

[1] American Concrete Pavement Association, Design and Construction of Joints for Concrete Streets, ACPA, Washington, DC, USA, 1992.
[2] P. Taylor, L. Sutter, and J. Weiss, "Investigation of deterioration of joints in concrete pavements," Tech. Rep. 09361, Iowa State University, Ames, IA, USA, 2012.

[3] W. Li, M. Pour-Ghaz, J. Castro, and J. Weiss, "Water absorption and critical degree of saturation relating to freezethaw damage in concrete pavement joints," Journal of $\mathrm{Ma}$ terials in Civil Engineering, vol. 24, no. 3, pp. 299-307, 2012.

[4] N. Thaulow and S. Sahu, "Mechanism of concrete deterioration due to salt crystallization," Materials Characterization, vol. 53, no. 2-4, pp. 123-127, 2004.

[5] G. A. Julio-Betancourt, Effect of de-icer and anti-icer checmilcas on the durability, microstructure, and properties of cement-based materials, Ph.D. dessertation, University of Toronto, Toronto, ON, Canada, 2009.

[6] L. Sutter, K. Peterson, S. Houton, T. Van Dam, and D. Johnston, "Petrographic evidence of calcium oxychloride formation in mortar exposed to magnesium chloride solution," Cement and Concrete Research, vol. 36, no. 8, pp. 1533-1541, 2006.

[7] W. A. Tasong, J. C. Cripps, and C. J. Lynsdale, "Aggregatecement chemical interactions," Cement and Concrete Research, vol. 28, no. 7, pp. 1037-1048, 1998.

[8] Y. Farnam, A. Wiese, D. Bentz, J. Davis, and J. Weiss, "Damage development in cementitious materials exposed to magnesium chloride deicing salt," Construction and Building Materials, vol. 93, pp. 384-392, 2015.

[9] J. Weiss and Y. Farnam, "Concrete pavement joint deterioration recent findings to reduce the potential for damage," in Map Brief June, CP Road Map, FHWA, Washington, DC, USA, 2015.

[10] H. Lee, R. D. Cody, A. M. Cody, and P. G. Spry, "Effects of various deicing chemicals on pavement concrete deterioration," in Proceedings of Mid-Continent Transportation Symposium Proceeding, p. 151, Ames, IA, USA, May 2000.

[11] L. Sutter, T. Van Dam, K. R. Peterson, and D. P. Johnston, "Long-Term effects of magnesium chloride and other concentrated salt solutions on pavement and structural Portland and structural Portland cement concrete," Journal of the Transportation Research Board, vol. 1979, pp. 60-68, 2006.

[12] S. Monosi and M. Collepardi, "Chemical attack of magnesium chloride on the Portland cement paste," IL Cemento, vol. 90, pp. 169-173, 1993.

[13] K. Peterson, G. Julio-Betancourt, L. Sutter, R. D. Hooton, and D. Johnston, "Observations of chloride ingress and calcium oxychloride formation in laboratory concrete and mortar at $5^{\circ} \mathrm{C}$," Cement and Concrete Research, vol. 45, pp. 79-90, 2013.

[14] D. M. Roy, M. W. Grutzeck, D. Shi, and G. Lui, Cement Paste Aggregate Interface Microstructure, SHRP-C-629, 1993.

[15] C. W. Correns, "Growth and dissolution of crystals under linear pressure," Discussions of the Faraday Society, vol. 5, pp. 267-271, 1949.

[16] A. Delagrave, J. P. Bigas, J. P. Ollivier, J. Marchand, and M. Pigeon, "Influence of the interfacial transition zone on the chloride diffusivity of mortars," Advanced Cement Based Materials, vol. 5, no. 3-4, pp. 86-89, 1997.

[17] P. Taylor, J. K. Zhang, and X. Wang, Investigation of Deterioration of Joints in Concrete Pavements, Tech. Rep. TPF5(224), Iowa State University, Ames, IA, USA, 2015.

[18] P. Gegout, E. Revertegat, and G. Moine, "Choride ion attack on low water-cement ratio pastes containing silica fume," in Proceedings of the Fourth International Conference on the Use of Fly Ash, Silica Fume, Slag and Natural Pozzolans in Concrete, ACI SP-132, V. Malhotra, Ed., pp. 1471-1490, Istanbul, Turkey, 1992. 
[19] D. Hoffmann, "Changes in structure and chemistry of cement mortars stressed by a sodium chloride solution," Cement and Concrete Research, vol. 14, no. 1, pp. 49-56, 1984.

[20] J. J. Valenza II and G. W. Scherer, "A review of salt scaling: II. Mechainmsms," Journal of Cement and Concrete Research, vol. 37, no. 7, pp. 1022-1034, 2007.

[21] J. Zhang, Investigation of deterioration of joints in concrete pavements, Ph.D. dissertation, Iowa State University, Ames, IA, USA, 2013.

[22] S. Bhanja and B. Sengupta, "Influence of silica fume on the tensile strength of concrete," Cement and Concrete Research, vol. 35, no. 4, pp. 743-747, 2005.

[23] J. Zhang, P. C. Taylor, and C. Shi, "Investigation of approaches for improving interfacial transition zone-related freezingand-thawing resistance in concrete pavements," ACI Materials Journal, vol. 112, no. 5, 2013. 


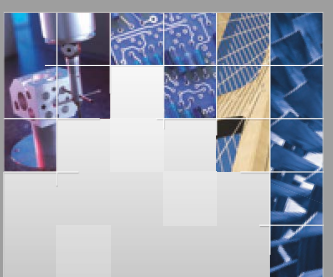

\section{Enfincering}
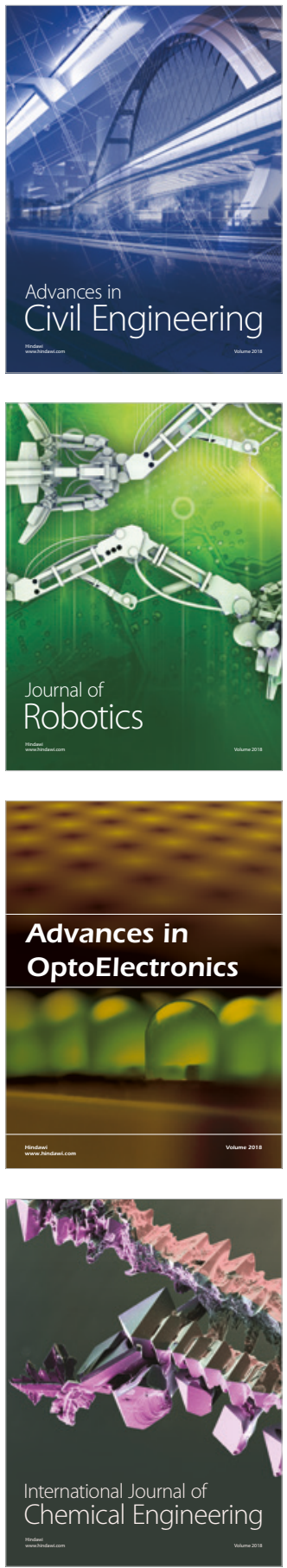

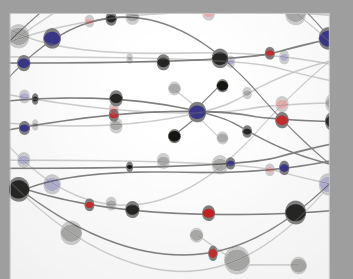

\section{Rotating \\ Machinery}

The Scientific World Journal

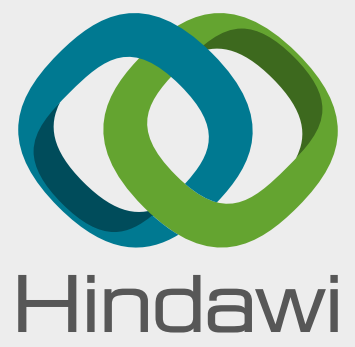

Submit your manuscripts at

www.hindawi.com
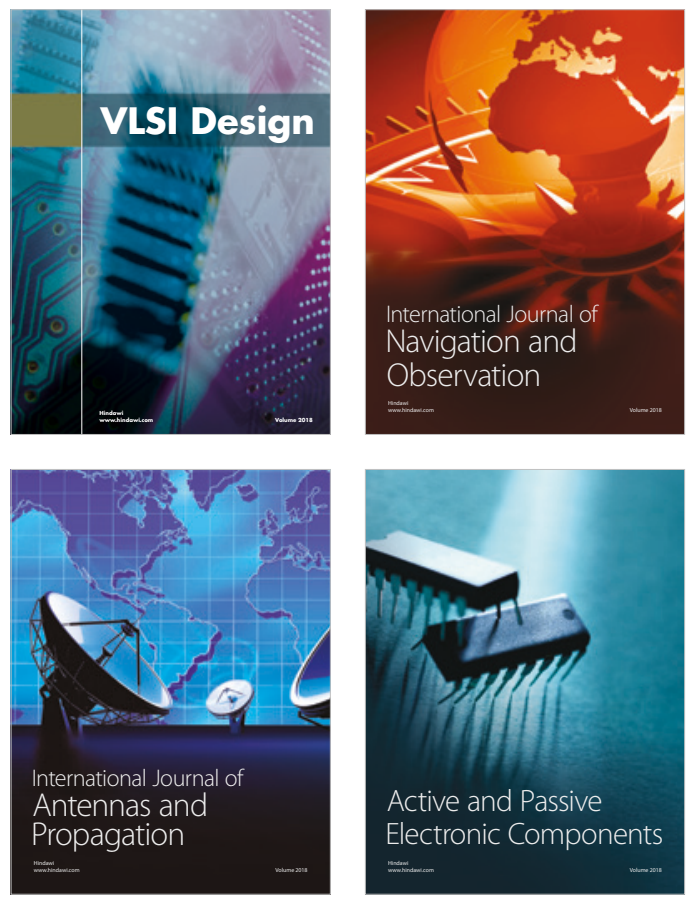
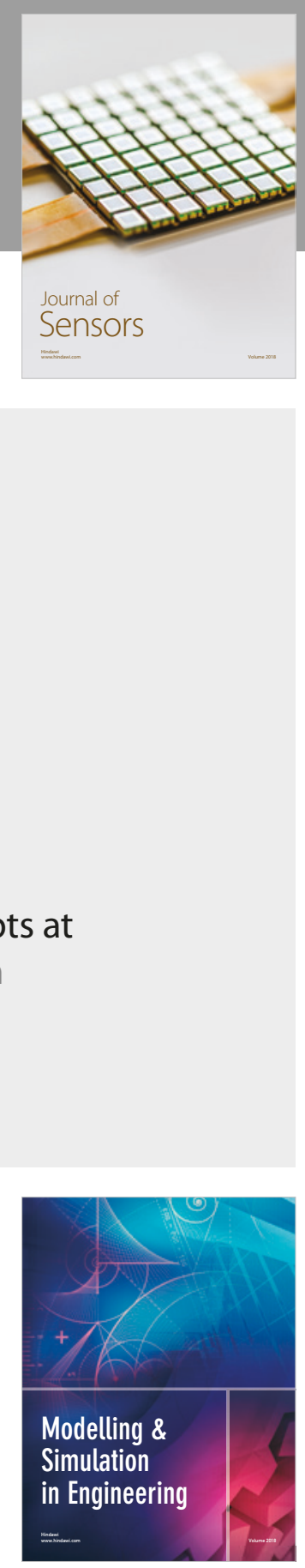

\section{Advances \\ Multimedia}
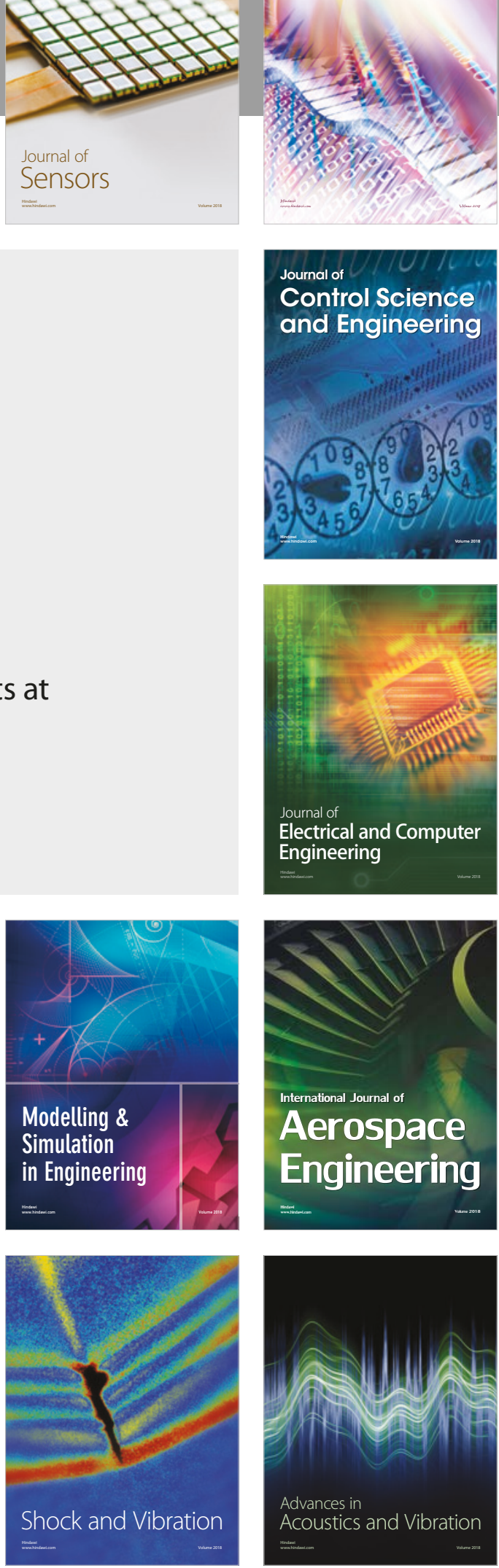